\title{
Preexposure to explicitly unpaired conditioned and unconditioned stimuli retards conditioned response emergence
}

\author{
WILLIAM F. PROKASY, CHARLES W. SPURR, and NANCY A. GOODELL \\ University of Utah, Salt Lake City, Utah 84112
}

\begin{abstract}
An aversive nictitating membrane conditioning experiment, with rabbit subjects, was designed to address two questions concerning stimulus contingencies experienced prior to the emergence of conditioned responses (CRs). Will initial conditioned stimulus/unconditioned stimulus (CS-US) pairings insufficient in number to result in CRs have a between-sessions enhancement effect on subsequent performance? Will exposure to explicitly unpaired CSs and USs retard the emergence of CRs? There was no evidence of a between-sessions enhancement effect. However, exposure to unpaired CSs and USs did delay CR emergence, although it did not have any effect once CRs had emerged. It was concluded that the initial negative CS-US contingency experience was more likely to have retarded the detection of the CS-US pairing contingency than to have affected response selection and/or organization.
\end{abstract}

It is evident that rabbit subjects learn that a conditioned stimulus/unconditioned stimulus (CS-US) contingency exists substantially before they exhibit any evidence of a nictitating-membrane conditioned response (CR). First, differential cardiac activity occurs in rabbits within 10 conditioning trials (Prokasy, 1965; Schneiderman, Smith, Smith, \& Gormezano, 1966), while typically as many as 20 or more conditioning trials are required before there is evidence of a nictitating-membrane CR (e.g., Prokasy, 1973). Second, recent evidence from the Thompson laboratory (Thompson, 1976) shows quite clearly that contingencyrelated multiple-unit activity in the hippocampus occurs in rabbits within 10 CS-US trials and that this activity appears before the nictitating-membrane response develops.

Given this information, two questions are posed. The first has to do with consolidation effects. If subjects are given enough paired trials to assure contingency detection, but not enough to permit CRs to emerge, will subsequent $C R$ acquisition be enhanced in a later conditioning session relative to that of subjects who do not receive a break between conditioning sessions? We already know that there is overnight enhancement from session to session with relatively few trials per training session (e.g., Hupka, Massaro, \& Moore, 1968), but we do not know the extent to which the enhancement is attributable to influences not associated directly with the fact that CRs are taking place.

The second question has to do with the kind of

This research was supported by National Science Foundation Grant BNS 75-10471 to the senior author, by a National Institute of Health predoctoral traineeship to the second author, and by National Institute of Health Biomedical Research Support Grant RR 07092 to the University of Utah. information received by subjects prior to CS-US pairing. If, as appears to be the case, subjects can detect contingencies rapidly, will exposure to a negative CS-US contingency (i.e., explicitly unpaired CS and US trials) retard the detection of a subsequent positive contingency (i.e., CS-US pairing) and thereby delay the emergence of CRs? Rate of CR acquisition has been shown to be retarded following extensive exposures to CS-alone trials (e.g., Solomon, Brennan, \& Moore, 1974) and to US-alone trials (Mis \& Moore, 1973). In the present experiment, we are concerned with relatively few exposures to CS and US, a number that assures contingency detection but that is not likely to be sufficient to result in inhibitory effects traceable strictly to the noncontingent presentation of either CS or US. A backward-pairing preexposure group was employed in addition to other controls. The purpose was, first, to determine if there would be any negative transfer effect of backward pairing, and second, to assure that any effect of the explicitly unpaired contingency would not be a generalized effect that might occur as a result of any contingency other than that of CS-US pairing.

Both questions can be understood better within the framework of the two-phase model of conditioning (Prokasy, 1972, 1973, 1974). There are two phases required to describe performance across trials. During Phase 1 there is no departure from baseline responding and it is during this phase that contingency detection and response selection (or development) must take place (see, e.g., Prokasy, Clark, Williams, \& Spurr, 1975). Changes in response likelihood are observed in Phase 2. Response probability on Trial $i, P_{i}$ is expressed as: (1) $\mathrm{P}_{\mathrm{i}}=\mathrm{P}_{\mathrm{o}}, \mathrm{i}=1, \mathrm{~K}$; (2) $\mathrm{P}_{\mathrm{i}}=\mathrm{P}_{\mathrm{i}-1}+\theta_{1}\left(\lambda_{1}-\mathrm{P}_{\mathrm{i}-1}\right)$, $\mathrm{i}>\mathrm{K}$, given $\mathrm{CR}$, US on Trial $\mathrm{i}-1$; (3) $\mathrm{P}_{\mathrm{i}}=\mathrm{P}_{\mathrm{i}-1}+$ 
$\theta_{2}\left(\lambda_{2}-\mathrm{P}_{\mathrm{i}-1}\right), \mathrm{i}>\mathrm{K}$, given $\mathrm{CR}$, US on Trial $\mathrm{i}-1$; (4) $P_{i}=P_{i-1}+\theta_{3}\left(\lambda_{3}-P_{i-1}\right), i>K$, given $C R$, US on Trial $\mathrm{i}-1$; (5) $\mathrm{P}_{\mathrm{i}}=\mathrm{P}_{\mathrm{i}-1}+\theta_{4}\left(\lambda_{4}-\mathrm{P}_{\mathrm{i}-1}\right)$, $\mathrm{i}>\mathrm{K}$, given $\overline{C R}$, US on Trial $i-1$; where $P_{0}$ is the initial response likelihood, the $\theta$ s are rate-change parameters, the $\lambda s$ are operator limits, and $\mathrm{K}$ is the trial of transition between Phase 1 and Phase 2 .

Within the framework of the model, the first problem is to determine whether or not, following contingency detection, there is an overnight consolidation effect that reduces the number of trials required for response selection (or development) and thereby reduces the duration of Phase 1 (i.e., the value of $\mathrm{K}$ ). The second problem is to determine whether or not nonpairing contingencies in a preexposure session delay the acquisition of a CS-US contingency and thereby increase the duration of Phase 1. Note that in either instance nothing precludes a treatment effect during Phase 2. Any Phase 2 effect, however, would be interpreted to be an effect directly on the response system rather than on any interference with or enhancement of the detection of a CS-US contingency.

\section{METHOD}

\section{Subjects}

Data are reported for 105 adult male albino rabbits, weighing 2.5-3.5 kg each, obtained from the University of Utah Vavarium. Due to either apparatus malfunction or a failure to show CRs within 250 conditioning trials, eight subjects were dropped, with no more than two being lost from any one group. The subjects were maintained on ad-lib food and water throughout the experiment except when in the conditioning apparatus.

\section{Apparatus and Procedure}

Rabbits were run four at a time in a lighted room in visually isolated chambers. The restrainers were of the type described by Gormezano (1966). Membrane responses were recorded as a dc signal with a Giannini potentiometer mounted on the rabbit's head and hooked into a nylon loop sutured into the right nictitating membrane of the day prior to the first experimental session. If the voltage signal met the softwareprogrammed criteria for a $C R$ (a signal equivalent to a minimum nictitating-membrane response extension of less than $1 \mathrm{~mm}$ occurring during the final $200 \mathrm{msec}$ of the interstimulus interval), the signal was converted to a latency from CS onset and stored on linc tape by a PDP-12 computer.

Stimulus parameters remained essentially the same over both days of the experiment. The CS was a $1,000-\mathrm{Hz} 30-\mathrm{dB}$ tone (re .0002 dynes $/ \mathrm{cm}^{2}$ ) of $250-\mathrm{msec}$ duration and the US was a $1.0-\mathrm{mA}$ infraorbital eyeshock of $50-\mathrm{msec}$ duration delivered through two stainless steel wound clips (Clay-Adams, $9 \mathrm{~mm}$ ). The CS-US interval was $250 \mathrm{msec}$ during all paired presentations. The intertrial interval was 40,50 , or $60 \mathrm{sec}$, averaging $50 \mathrm{sec}$. A 65-dB continuous background white noise was used throughout both sessions. All subjects were given a 15 -min adaptation period in the apparatus prior to each session.

Subjects were randomly assigned to one of seven experimental groups. The groups were designated according to the Day 1 preacquisition session treatment as follows: Group 1 $(\mathrm{N}=14)$ received 15 forward-paired trials; Group $2(\mathrm{~N}=15)$ received 15 backward-paired trials; Group $3(\mathrm{~N}=15)$ received 15 explicitly unpaired presentations of both the CS and the US; Group $4(\mathrm{~N}=15)$ received $15 \mathrm{CS}$ presentations; Group 5 $(N=15)$ received 15 US presentations; Group $6 \quad(N=16)$ received no stimulus presentations while restrained in the apparatus; and Group $7(\mathrm{~N}=15)$ was not put into the apparatus at all on Day 1. On Day 2 all subjects were given 250 paired CS-US presentations.

\section{RESULTS}

Best-fit parameters were obtained separately for each subject using the computer subroutine STEPIT (Chandler, 1969). Estimates were obtained for each of the following Phase 2 assumption categories: (1) $\lambda_{1}=\lambda_{2}, \theta_{1}=\theta_{2}$; (2) $\lambda_{1}=\lambda_{2}, \theta_{1} \neq \theta_{2}$; (3) $\lambda_{1} \neq \lambda_{2}$, $\theta_{1}=\theta_{2}$; (4) $\lambda_{1} \neq \lambda_{2}, \theta_{1} \neq \theta_{2}$. Based upon a goodnessof-fit index, subjects were then classified into one of

Table 1

Mean Parameter Estimates and Terminal Response Probability (TRP) for Session 2

\begin{tabular}{|c|c|c|c|c|c|c|c|c|}
\hline Group & TRP & $\mathrm{K}^{*}$ & Assumption & $\mathbf{n}$ & $\theta_{1}$ & $\lambda_{1}$ & $\theta_{2}$ & $\lambda_{2}$ \\
\hline 1 & .839 & 25.20 & $\begin{array}{l}\mathrm{A} \\
\mathrm{C}\end{array}$ & $\begin{array}{l}8 \\
6\end{array}$ & $\begin{array}{l}.339 \\
.600\end{array}$ & $\begin{array}{l}.877 \\
.928\end{array}$ & $\begin{array}{l}.339 \\
.600\end{array}$ & $\begin{array}{l}.877 \\
.448\end{array}$ \\
\hline 2 & .821 & 28.75 & $\begin{array}{l}\text { A } \\
\text { C }\end{array}$ & $\begin{array}{l}8 \\
7\end{array}$ & $\begin{array}{l}.298 \\
.408\end{array}$ & $\begin{array}{l}.909 \\
.880\end{array}$ & $\begin{array}{l}.298 \\
.408\end{array}$ & $\begin{array}{l}.909 \\
.449\end{array}$ \\
\hline 3 & .721 & 48.29 & $\begin{array}{l}\text { A } \\
\text { C } \\
\text { D }\end{array}$ & $\begin{array}{l}7 \\
7 \\
1\end{array}$ & $\begin{array}{r}.203 \\
.532 \\
1.000\end{array}$ & $\begin{array}{l}.843 \\
.866 \\
.848\end{array}$ & $\begin{array}{l}.208 \\
.532 \\
.263\end{array}$ & $\begin{array}{l}.843 \\
.408 \\
.034\end{array}$ \\
\hline 4 & .845 & 27.20 & $\begin{array}{l}\mathrm{A} \\
\mathrm{C}\end{array}$ & $\begin{array}{r}10 \\
5\end{array}$ & $\begin{array}{l}.229 \\
.458\end{array}$ & $\begin{array}{l}.890 \\
.926\end{array}$ & $\begin{array}{l}.229 \\
.458\end{array}$ & $\begin{array}{l}.890 \\
.353\end{array}$ \\
\hline 5 & .767 & 37.25 & $\begin{array}{l}\text { A } \\
\text { C }\end{array}$ & $\begin{array}{r}12 \\
3\end{array}$ & $\begin{array}{l}.324 \\
.509\end{array}$ & $\begin{array}{l}.859 \\
.795\end{array}$ & $\begin{array}{l}.324 \\
.509\end{array}$ & $\begin{array}{l}.859 \\
.291\end{array}$ \\
\hline 6 & .839 & 32.30 & $\begin{array}{l}\mathrm{A} \\
\mathrm{C}\end{array}$ & $\begin{array}{r}14 \\
2\end{array}$ & $\begin{array}{l}.321 \\
.450\end{array}$ & $\begin{array}{l}.873 \\
.826\end{array}$ & $\begin{array}{l}.321 \\
.450\end{array}$ & $\begin{array}{l}.873 \\
.503\end{array}$ \\
\hline 7 & .839 & 30.80 & $\begin{array}{l}\text { A } \\
\text { C } \\
\text { D }\end{array}$ & $\begin{array}{r}12 \\
2 \\
1\end{array}$ & $\begin{array}{l}.309 \\
.222 \\
.778\end{array}$ & $\begin{array}{l}.878 \\
.882 \\
.942\end{array}$ & $\begin{array}{l}.309 \\
.222 \\
.390\end{array}$ & $\begin{array}{l}.878 \\
.438 \\
.088\end{array}$ \\
\hline
\end{tabular}

*Averaged across all assumptions within each group. 
the four assumption categories. The details for making this classification are provided elsewhere (Clark \& Prokasy, 1976; Prokasy et al., 1975) and will not be repeated here. $P_{o}$ was assumed to be .02 for all subjects.

Table 1 contains the mean parameter estimates for Phases 1 and 2, the number of subjects falling in each assumption category, and terminal performance level over the final 100 trials of training. It is to be noted that, with two exceptions, all subjects were categorized under either Assumption 1 or Assumption 3. Moreover, all subjects classified either Assumption 3 or under Assumption 4 had $\lambda_{1}$ greater than $\lambda_{2}$, a typical finding with this preparation (e.g., Prokasy, 1973).

To determine whether there was any overnight facilitation associated with subjects receiving their first 15 paired trials during the pretraining session, a Mann-Whitney U test was employed to contrast the values of $\mathrm{K}$ between Groups 1 and $6 . \mathrm{K}$ was estimated in both groups based upon Session 2 performance but, in view of the fact that Group 1 had received 15 paired trials during the preexposure session, it was necessary to add a value of 15 to the $K$ value for each subject in that group. Median $\mathrm{K}$ was less for Group 1, but the difference was not significant $[U(14,16)=111.5]$. In addition, there were no reliable between-groups effects found in the parameter estimates for Phase 2. Thus, there is no evidence of overnight facilitation either on the duration of Phase 1 or on the parameters of Phase 2. As Table 1 indicates, there was no difference in terminal performance levels, either.

To determine whether the use of explicitly unpaired CS and US trials during the pretraining session had a retarding effect upon acquisition, Groups 3 and 6 were contrasted. The duration of Phase 1 , indexed by $K$, was significantly longer in Group 3 than in Group 6 $[\mathrm{U}(15,16)=58.0]$. No reliable between-groups differences were found in the parameter estimates of Phase 2 or in terminal response levels. Thus, exposure to explicitly unpaired CSs and USs retarded acquisition by delaying the onset of Phase 2 , but did not affect performance during Phase 2.

Although Groups 3 and 6 did differ in the duration of Phase 1, the contrast between the two groups was not sufficient to assure that the effect was attributable to the negative contingency. To this end, Groups 4 and 5, the CS-alone and US-alone groups, respectively, were also contrasted with Group 6. There were no reliable differences among these groups either in parameter estimates or in terminal response levels. Group 2, which received US-CS pairings during the preexposure session, did receive contingency trials prior to the conditioning session and received, as well, as many CS and US prexposures as did Group 3. There were no reliable differences in parameter estimates or terminal response levels between Groups 2 and 6.

\section{DISCUSSION}

The first question posed for this study was that of whether there is any evidence of overnight enhancement on conditioning performance when the overnight break is taken following a time when CS-US contingency detection could be said to have occurred, but yet prior to the emergence of a CR. Within the limits of failing to reject the null hypothesis, it can be said that there is no evidence of pre-CR overnight enhancement, an effect that is quite powerful once CRs have emerged (e.g., Hupka et al., 1968). The duration of Phase 1 (i.e., the pre-CR emergence phase) did not differ as a function of whether the 15 initial paired trials occurred as part of the extended conditioning session or in a brief session preceding by $24 \mathrm{~h}$ the extended session. The provisional conclusion is that overnight enhancement at most only minimally reflects associative-system changes and more likely reflects variables determining response generation (i.e., variables that operate directly during Phase 2).

The more interesting outcome relates to the second question: Are there contingencies during a pretraining phase that can retard the detection of a CS-US contingency? The answer to this would appear to be positive. Specifically, the introduction of explicitly unpaired CSs and USs during a preexposure session extended the duration of Phase 1 during conditioning relative to that of controls receiving preexposures that did not include a negative correlation of CS and US. Thus, the introduction of experience with a CS and US that are negatively correlated increased Phase 1 duration when the negative correlation became positive.

If the effect of the negative correlation between CS and US during preexposure reflected simply the fact that CS-US contingencies other than CS-US pairing produce interference, then preexposure to US-CS pairings might similarly have been expected to affect the duration of Phase 1 . This did not happen. The present results suggest, therefore, that the negative contingency itself, that is, a situation in which the conditional likelihood of the US occurring in the proximity of the CS is zero and vice versa (see, e.g., Prokasy, 1965), retards the transition from Phase 1 to Phase 2.

While we have interpreted the effect of the negative contingency to be one of retarding the detection of CS-US pairing, an alternative possibility is that the negative correlation between CS and US retarded response-strength development. This is not considered to be a likely explanation, however, since there were no Phase 2 effects of the preexposure experience. If the negative contingency had its effect on the development of response strength or on the ease with which a CS could elicit a CR, there is every reason for that impact to be reflected in the parameter estimates for Phase 2.

One other way in which the negative contingency could have functioned is to have delayed the selection of a particular CR (i.e., the membrane response) from an unspecified array of possible responses. Prokasy et al. (1975) have pointed out that Phase 1 must include a response selection and/or organization segment, and it is possible that the negative contingency extended the time, following CS-US contingency detection, required to complete that segment of Phase 1 . While this, in our view, does not appear to be a plausible explanation, one way to assess this would be through multiple-unit recording from the dorsal hippocampus. As Thompson and his associates have shown (Thompson, 1976), multiple-unit activity appears after fewer than 10 CS-US pairings. If this activity is not delayed following a negative CS-US contingency exposure, but Phase 1 duration is extended, it might then be argued that the negative contingency operates not on CS-US pairing detection, but on response selection. 


\section{REFERENCES}

Chandler, J. P. STEPIT: Finds local minima of a smooth function of several parameters. Journal of Behavior Science, 1969, 14, 81-82.

Clark, C. G., \& Prokasy, W. F. Manipulation of responsecontingent unconditioned-stimulus intensity in human eyelid conditioning: A two-phase model analysis. Memory \& Cognition, 1976, 4, 277-282.

Gormezano, I. Classical conditioning. In J. B. Sidowski (Ed.), Experimental methods and instrumentation in psychology. New York: McGraw-Hill, 1966.

Hupka, R. B., Massaro, D. W., \& Moore, J. W. Yoked comparisons of instrumental-avoidance and classical conditioning of the rabbit nictitating membrane response as a function of interstimulus interval and number of trials per day. Psychonomic Science, 1968, 12, 93-94.

MIs, F. W., \& MoORE, J. W. Effects of preacquisition UCS exposure on classical conditioning of the rabbit's nictitating membrane response. Learning and Motivation, 1973, 4, 108-114.

Prokasy, W. F. Classical eyelid conditioning: Experimenter operations, task demands, and response shaping. In W. F. Prokasy (Ed.), Classical conditioning: $A$ symposium. New York: Appleton-Century-Crofts, 1965.

Prokasy, W. F. Developments with the two-phase model applied to human eyelid conditioning. In A. H. Black \&
W. F. Prokasy (Eds.), Classical conditioning II: Current research and theory. New York: Appleton-Century-Crofts, 1972.

Prokasy, W. F. A two-phase model account of aversive classical conditioning performance in humans and rabbits. Learning and Motivation, 1973, 4, 247-258.

Prokasy, W. F. Discriminated avoidance vs. classical conditioning: A two-phase model analysis. Animal Learning \& Behavior, 1974, 2, 257-261.

Prokasy, W. F., Clark, C. G., Williams, W. C., \& Spurr, C. W. Conditioned response-contingent delays of the unconditioned stimulus in human aversive conditioning. Journal of Experimental Psychology: Human Learning and Memory, 1975, 1, 513-520.

Schneiderman, N., Smith, M. C., Smith, A. C., \& Gormezano, I. Heart rate classical conditioning in rabbits. Psychonomic Science, 1966, 6, 241-242.

Solomon, P. R., Brennan, G., \& Moore, J. W. Latent inhibition of the rabbit's nictitating membrane response as a function of CS intensity. Bulletin of the Psychonomic Society, 1974, 4, 445-448.

Thompson, R. F. The search for the engram. American Psychologist, 1976, 31, 209-227.

(Received for publication May 17, 1978.) 